\title{
Kedarcidin Chromophore-Synthesis of Its Proposed Structure and Evidence for a Stereochemical Revision
}

\author{
Feng Ren, Philip C. Hogan, Alan J. Anderson, and Andrew G. Myers ${ }^{\star}$ \\ Department of Chemistry and Chemical Biology, Harvard University, Cambridge, Massachusetts \\ 02138
}

\begin{abstract}
A convergent, enantioselective synthesis of the proposed structure of kedarcidin chromophore (1) is described. The route is 24 steps in the longest linear sequence (beginning with the commercial reagent 2,3-O-isopropylidene-D-erythronolactone) with an average yield of 75\% per step (overall yield: $0.1 \%$ ). Our ${ }^{1} \mathrm{H}$ NMR data for $\mathbf{1}$ do not coincide with the data reported for kedarcidin chromophore. We have re-analyzed the original data and here propose a stereochemical revision at position $\mathrm{C} 10$, the site of attachment of the ${ }_{\mathrm{L}}$-mycarose carbohydrate residue to the chromophore core (structure 2).
\end{abstract}

The structure of the chromophore component of the cytotoxic protein-chromophore complex kedarcidin was determined by researchers at BMS in 1992 on the basis of an extensive spectroscopic analysis of the isolated chromophore and its degradation products, an undertaking that was greatly complicated by the reactivity of the chromophore and its low natural abundance. ${ }^{1}$ The original structural proposal was modified (as 1, Scheme 1 and Figure 1) by Hirama and co-workers in 1997, thereby transforming the originally proposed $\alpha$-azatyrosyl residue of the ansa-bridge to the corresponding $\beta$-amino acid derivative and reversing the handedness of the molecule. ${ }^{2}$ Here, we describe an unambiguous, enantioselective synthesis of structure 1. Our spectroscopic data show that the structure of kedarcidin chromophore must be further revised, we suggest by epimerization of the mycarose-bearing carbon, C10 (structure 2, Figure 1, see below).

We synthesized structure 1 using a highly convergent route (Scheme 1). The sequence was initiated with the azatyrosyl dibromide $\mathbf{3}$ as starting material (>95\% ee), prepared by extension of our published route to the corresponding tert-butyldimethylsilyl (TBS)-alkynyl derivative ${ }^{3}$ using a different, auxiliary-based route to the $\beta$-amino acid component ${ }^{4}$ (see Supporting Information; use of the triethylsilyl (TES)-alkynyl group within $\mathbf{3}$ is a refinement that allows for a simultaneous deprotection reaction later, $\mathbf{8} \rightarrow \mathbf{9}$, vide infra). The methyl ester group of $\mathbf{3}$ was transformed into the corresponding 9-fluorenylmethyl (Fm) ester ${ }^{5}$ by saponification with lithium hydroperoxide and esterification of the resulting carboxylic acid with 9-fluorenemethanol using 2-methyl-6-nitrobenzoic anhydride as an activating agent (93\%, two steps). ${ }^{6}$ Cleavage of the $\mathrm{N}$-tert-butoxycarbonyl (BOC) protective group with trimethylsilyl triflate-2,6-lutidine ${ }^{7}$ and, in the same flask, addition of saturated aqueous sodium bicarbonate solution and a solution of the pivaloyl-protected, hydroxybenzotriazoleactivated 2-naphthoic acid derivative $4^{8}$ in dichloromethane afforded the coupled product 5 in $97 \%$ yield (22-g scale). Selection of the pivaloyl group to protect the naphthol group in the latter step allowed for a mild, fluoride-based deprotection reaction in the final step of the

myers@chemistry.harvard.edu.

Supporting Information Available: Detailed experimental procedures and tabulated spectroscopic data $\left({ }^{1} \mathrm{H}\right.$ and ${ }^{13} \mathrm{C}$ NMR, FT-IR, and MS) for all new compounds. This material is available free of charge via the Internet at http://pubs.acs.org. 
sequence (vide infra). Sonogashira coupling of the dibromoolefin 5 with the $\alpha$-kedarosylated dialkyne component $6^{9}$ formed the cis-bromoolefin 7 in $50-60 \%$ yield. ${ }^{10}$ Although the stereoisomeric trans-coupling product was never observed, the (chromatographically separable) bis-coupling product was detected as a side product, one whose formation was never completely suppressed. Selective cleavage of the Fm ester in the presence of the pivaloate ester within $7\left(\mathrm{Et}_{3} \mathrm{~N}\right.$, THF) cleanly afforded the corresponding carboxylic acid, which was cyclized using the Shiina macrolactonization protocol ${ }^{11}$ to provide the macrolactone 8 (atropisomeric mixture, see Scheme 1 for details concerning the conformations of this and subsequent macrocyclic intermediates). The macrolactonization reaction could be performed on the gram-scale without diminishing its yield (66\%). Both TES-alkynyl protective groups of $\mathbf{8}$ were selectively cleaved in the presence of the two silyl ethers by the Hirama procedure $\left(\mathrm{AgNO}_{3}, \mathrm{H}_{2} \mathrm{O}, \mathrm{THF}\right),{ }^{12}$ providing the substrate for intramolecular oxidative acetylenic coupling $(\mathbf{9}, 73 \%$ yield). At this point, a second macrocyclization reaction was performed employing modified Eglinton conditions $\left(\mathrm{Cu}(\mathrm{OAc})_{2}, \mathrm{CuI}, \mathrm{THF}\right.$, pyridine $){ }^{3,13}$ producing the macrobicyclic intermediate $\mathbf{1 0}$. The latter product was found to be extremely unstable and, for this reason, was directly subjected to transannular cyclization $(\mathbf{1 0} \rightarrow \mathbf{1 1}) .{ }^{14}$ Thus, sequential treatment of a solution of the macrobicyclic vinyl bromide $\mathbf{1 0}$ in THF-toluene $\left(1: 1\right.$, pre-stirred at $23{ }^{\circ} \mathrm{C}$ with $4 \AA$-MS for 15 min prior to cooling to $-78^{\circ} \mathrm{C}$ ) with LHMDS (1.0 M in THF, 6.0 equiv) then, after 2 min, with a solution of $t$ - $\mathrm{BuLi}$ in pentane $(1.7 \mathrm{M}, 8.0$ equiv) and immediately thereafter $(<5$ s) with a quenching solution of acetic acid in $\operatorname{THF}\left(1: 3,50\right.$ equiv), all at $-78^{\circ} \mathrm{C}$, afforded the tricyclic kedarcidin core structure $\mathbf{1 1}$ in 50\% yield. ${ }^{3}$ The TBS ether group of $\mathbf{1 1}$ was selectively removed in the presence of the diethyl-iso-propylsilyl ether of the kedarose sugar using $o$-nitrophenol-buffered tetra- $N$-butylammonium fluoride (TBAF) $;{ }^{3 a}$ this simultaneously cleaved the pivaloate ester, which was re-introduced (75\%, two steps $\mathbf{1 1} \rightarrow$ 12). Vanadium-directed epoxidation ${ }^{15}$ of the resulting allylic alcohol 12 was successful only with the hindered oxygen-atom source 1,1-diphenylethyl hydroperoxide, ${ }^{16}$ and afforded the epoxy alcohol 13 (28\% yield) as well as recovered starting material $(\mathbf{1 2}, 30 \%)$. The positionand stereo-selectivity of the epoxidation reaction as well as the conformation of the ansabridge were unambiguously established by several reinforcing NOE measurements within 13, as well as by chemical-shift and coupling-constant based arguments (see Supporting Information). An $\alpha$-glycosidic linkage was readily formed between $\mathbf{1 3}$ and the thioglycoside donor 14 (a mixture of anomers) using $\mathrm{AgPF}_{6}$ (2.5 equiv) as activator in the presence of 2,6di-tert-butyl-4-methylpyridine (DTBMP, 3.5 equiv), ${ }^{17}$ methodology previously developed by the Hirama group in their studies directed toward a synthesis of $\mathbf{1} .{ }^{18}$

The $\alpha$-mycarosylated product $\mathbf{1 5}$ was formed in $59 \%$ yield; approximately $15 \%$ of the starting material (13) was also recovered. Completion of the synthesis of $\mathbf{1}$ was achieved by dehydration of 15 using the Martin sulfurane in benzene (65\% yield), followed by global deprotection of the the dehydration product 16 (TBAF, $o$-nitrophenol, $\mathrm{CH}_{3} \mathrm{CN}$; ${ }^{3 \mathrm{a}}$ then $\mathrm{Et}_{3} \mathrm{~N} \bullet 3 \mathrm{HF}, 50 \%$ yield). Synthetic 1 provided spectroscopic data in complete accord with the proposed structure, as did its cycloaromatization product (formed in the presence of 1,4cyclohexadiene at $23{ }^{\circ} \mathrm{C}, 12 \mathrm{~h}, \sim 50 \%$ yield), but our ${ }^{1} \mathrm{H}$ NMR measurements differed substantially from those reported for the natural product. ${ }^{1}$ After rigorous reevaluation of our synthetic process, in which we re-confirmed all stereochemistry and each reaction outcome, as reported herein, ${ }^{19}$ we were led to carefully reconsider the original spectroscopic data for kedarcidin chromophore, leading us to identify inconsistencies between this data and both the original and the revised (1) structural assignments. ${ }^{1,2}$ In particular, the observation of a non-zero coupling between protons bound to C10 and C11 (3.1 Hz in DMSO- $\left.d_{6}\right)$, the lack of an NOE between the pyridyl C4' proton and H10, and the observation of an NOE between $\mathrm{H} 10$ and $\mathrm{H} 12 \mathrm{~b}$ (derived from hydride addition to $\mathrm{C} 12$ ) in the product of borohydrideinduced cycloaromatization of kedarcidin chromophore, ${ }^{1}$ suggested that the stereochemistry of $\mathrm{C} 10$ may have been misassigned (in synthetic 1, H10 appears as a sharp singlet in $\mathrm{C}_{6} \mathrm{D}_{6}$ 
and as a slightly broadened singlet in DMSO- $d_{6}$ ). On enquiry (Dr. John Leet, BMS), we have learned that the observed coupling between protons bound to $\mathrm{C} 10$ and $\mathrm{C} 11$ of authentic kedarcidin chromophore in $\mathrm{CDCl}_{3}$ (not previously reported) is $5.4 \mathrm{~Hz}$, which aligns perfectly with reported values for several (cis-oriented) like compounds in the literature. ${ }^{20}$ The revised structure we propose (2, Figure 1$)$ is consistent with all reported NOE, chemical-shift, and coupling-constant values. Further, it explains the observations that natural kedarcidin chromophore is a single atropisomer, whereas the trans-oriented molecule we synthesized (1) is a mixture of atropisomers, in two different NMR solvents (see Scheme 1). Presumably, kedarcidin chromophore ( $\mathbf{2}$, as proposed herein) cannot exist in the atropisomeric form that positions the chlorine atom toward the C10-mycarosyl substituent.

\section{Supplementary Material}

Refer to Web version on PubMed Central for supplementary material.

\section{Acknowledgments}

Generous financial support from the National Institutes of Health is gratefully acknowledged. Eli Lilly and Co. provided critical support in the form of a graduate fellowship to Mr. Feng Ren. We are especially grateful to Dr. John Leet and his colleagues at BMS, who were most helpful and accommodating in providing assistance to us throughout our investigations.

\section{References}

1. (a) Leet JE, Schroeder DR, Hofstead SJ, Golik J, Colson KL, Huang S, Klohr SE, Doyle TW, Matson JA. J. Am. Chem. Soc. 1992; 114:7946.(b) Leet JE, Schroeder DR, Langley DR, Colson KL, Huang S, Klohr SE, Lee MS, Golik J, Hofstead SJ, Doyle TW, Matson JA. J. Am. Chem. Soc. 1993; 115:8432.

2. Kawata S, Ashizawa S, Hirama M. J. Am. Chem. Soc. 1997; 119:12012.

3. (a) Myers AG, Goldberg SD. Angew. Chem. Int. Ed. 2000; 39:2732.(b) Myers AG, Hogan PC, Hurd AR, Goldberg SD. Angew. Chem. Int. Ed. 2002; 41:1062.(c) Myers AG, Hurd AR, Hogan PC. J. Am. Chem. Soc. 2002; 124:4583. [PubMed: 11971704]

4. (a) Zhou P, Chen B-C, Davis FA. Tetrahedron. 2004; 60:8003.(b) Ellman JA. Pure Appl. Chem. 2003; 75:39.

5. Kessler H, Siegmeier R. Tetrahedron Lett. 1983; 24:281.

6. Shiina I, Ibuka R, Kubota M. Chem. Lett. 2002; 286

7. Sakaitani M, Ohfune Y. J. Org. Chem. 1990; 55:870.

8. (a) Myers AG, Horiguchi Y. Tetrahedron Lett. 1997; 38:4363.(b) Hogan, PC. Thesis. Cambridge, MA: Harvard University; 2004.

9. Ren F, Hogan PC, Anderson AJ, Myers AG. Org. Lett. (submitted).

10. For examples of stereoselective (cis) palladium-mediated coupling reactions of 1,1-dihaloolefins, see: Shi J-C, Zeng X, Negishi E-I. Org. Lett. 2003; 5:1825. and pertinent references therein. [PubMed: 12762662]

11. Shiina I, Kubota M, Ibuka R. Tetrahedron Lett. 2002; 43:7535.

12. Sato I, Akahori Y, Iida K-i, Hirama M. Tetrahedron Lett. 1996; 37:5135.

13. Eglinton G, Galbreath AR. J. Chem. Soc. 1959; 889

14. Intermediates 10-13, 15, 16, and synthetic 1, were unstable in neat form. For this reason these compounds (when stored) were maintained in dilute solution. Yields were determined using an internal standard (see Supporting Information).

15. Rossiter BE, Verhoeven TR, Sharpless KB. Tetrahedron Lett. 1979; 20:4733.

16. Richardson WH, Hodge VF. J. Org. Chem. 1970; 35:4012.

17. Thioglycoside $\mathbf{1 4}$ was prepared from the commercial tartrate salt of Tylosin ( 3 steps). See Supporting Information for details. 
18. Lear MJ, Yoshimura F, Hirama M. Angew. Chem. Int. Ed. 2001; 40:946.

19. The relative and absolute stereochemistries of the kedarose, mycarose, and $\beta$-azatyrosine residues of kedarcidin chromophore have been rigorously established in prior work by comparison with authentic, synthetic standards. Refs 1b, 2, and Leet JE, Golik J, Hofstead SJ, Matson JA, Lee AY, Clardy J. Tetrahedron Lett. 1992; 33:6107.

20. (a) Comin MJ, Leitofuter J, Rodríguez JB. Tetrahedron. 2002; 58:3129.(b) Bickley JF, Roberts SM, Santoro MG, Snape TJ. Tetrahedron. 2004; 60:2569.(c) Perez M, Beau J-M. Tetrahedron Lett. 1989; 30:75. 


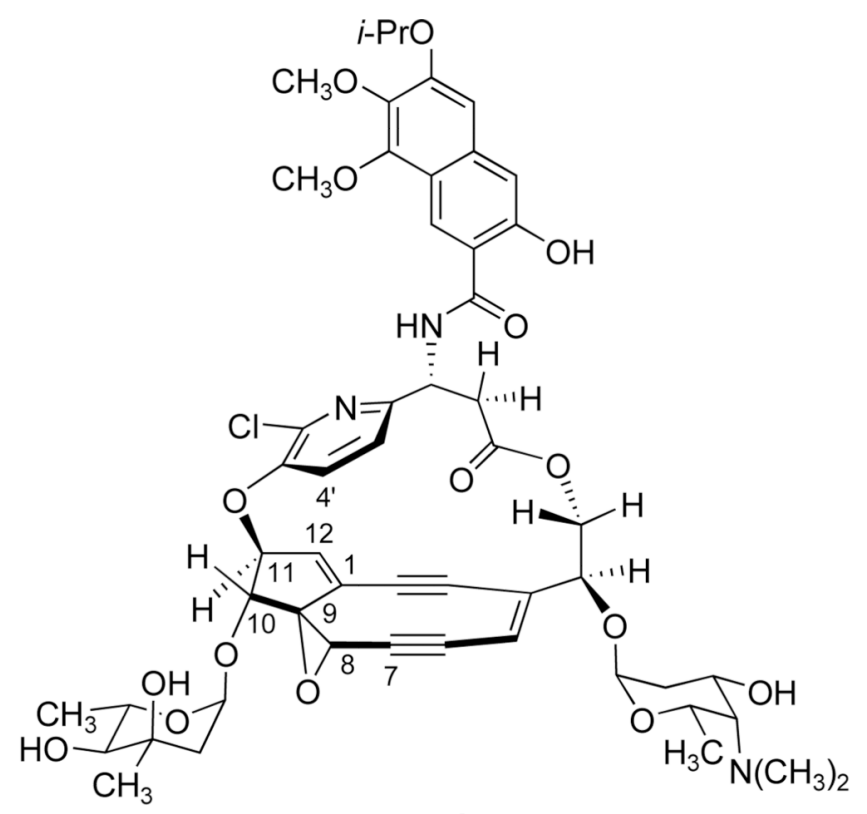

1

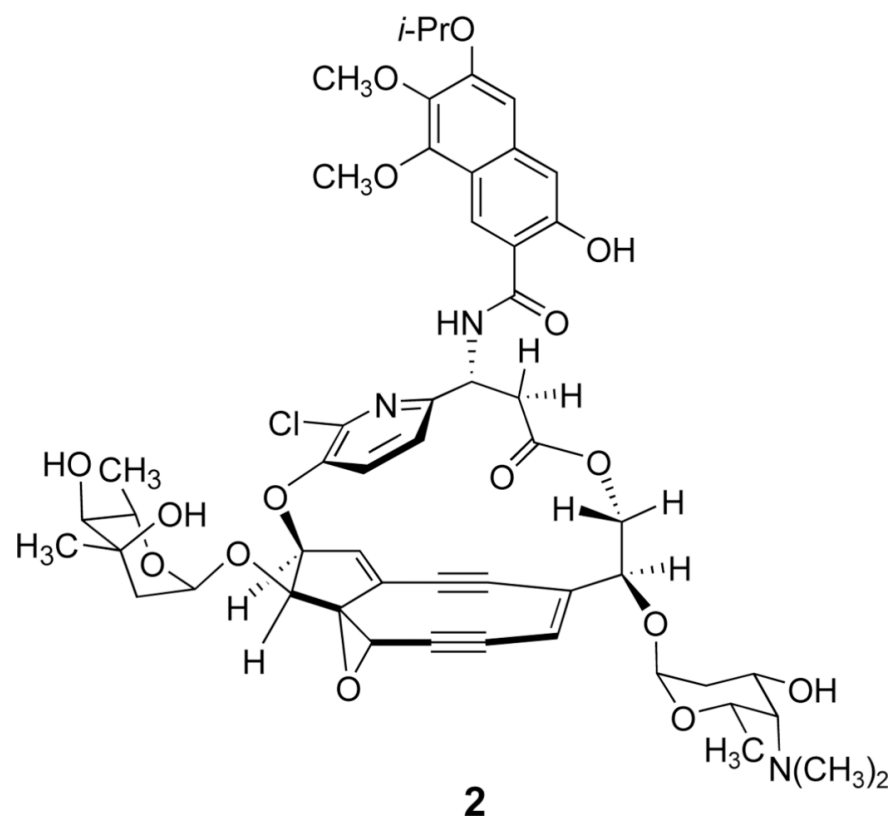

Figure 1.

Previous (1, ref 2) and current (2) structural revisions of kedarcidin chromophore. 

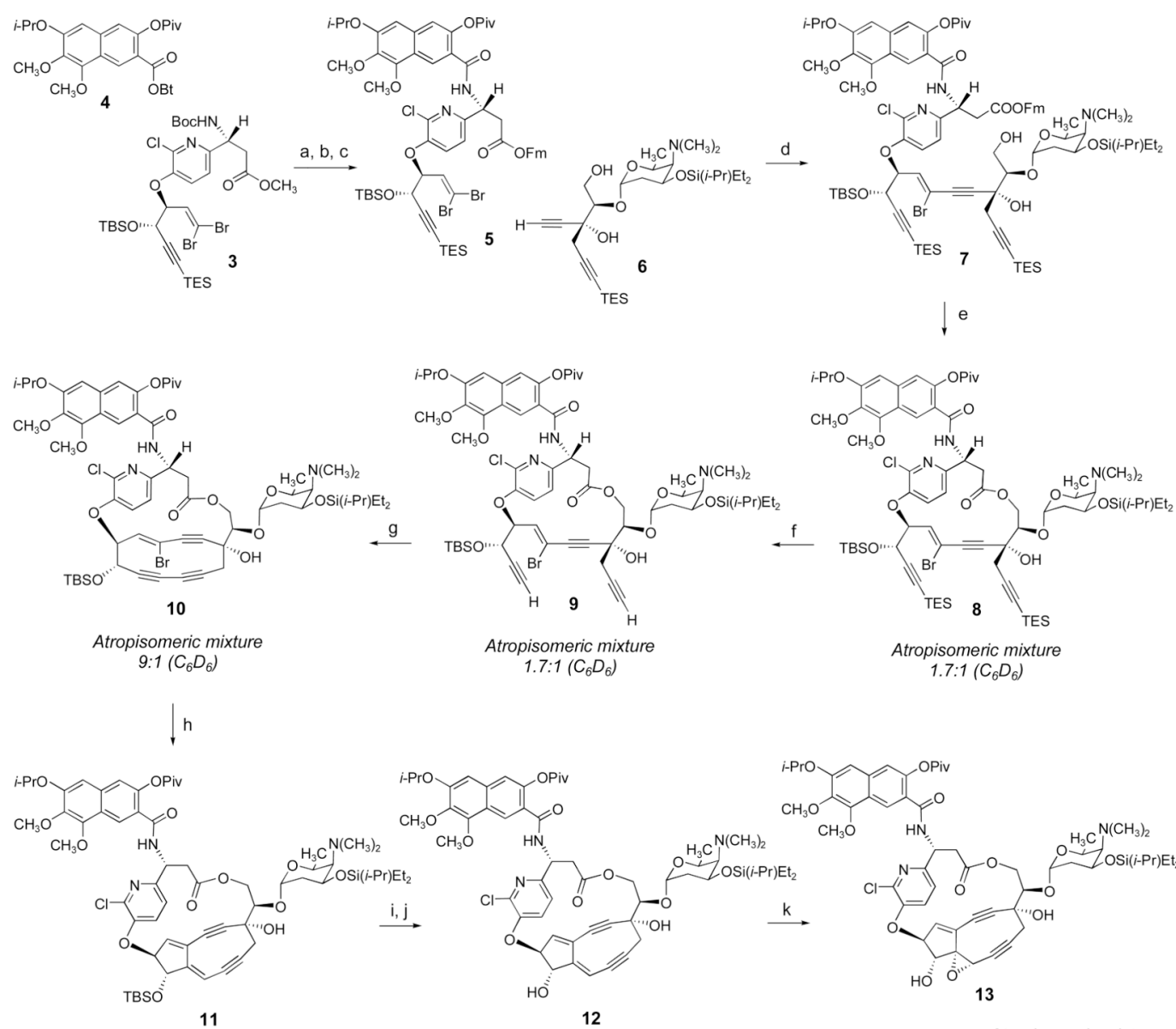

Single atropisomer

Single atropisomer

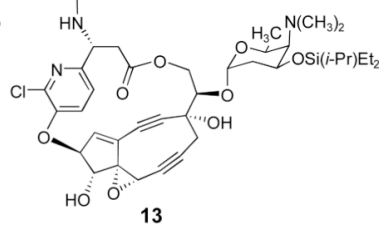

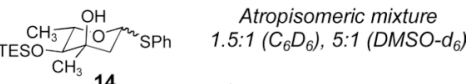
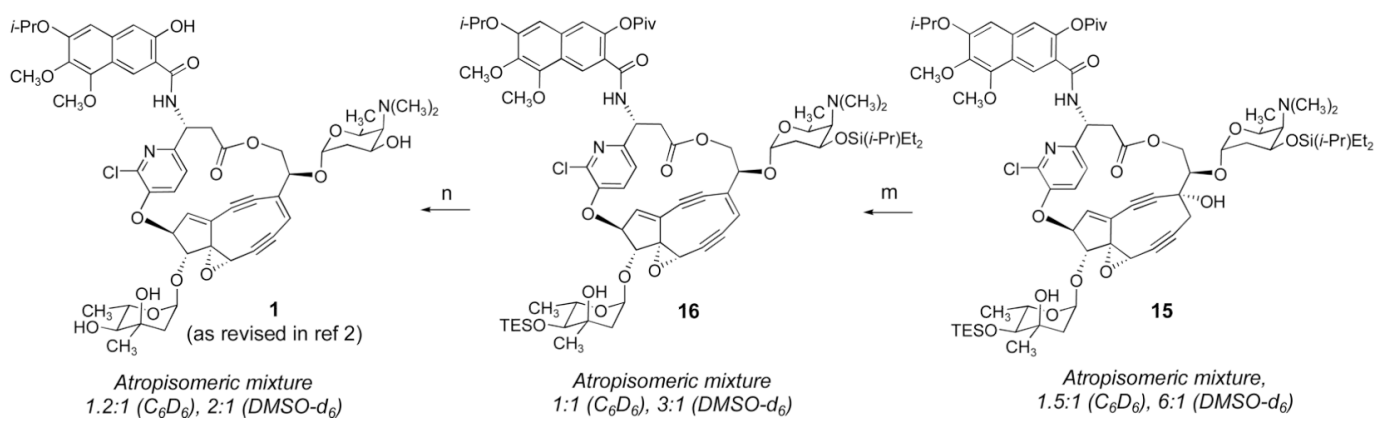

\section{Scheme 1.}

(a) 3, $\mathrm{LiOH}, \mathrm{H}_{2} \mathrm{O}_{2}$, THF, $\mathrm{H}_{2} \mathrm{O}, 23{ }^{\circ} \mathrm{C}$; (b) 9-fluorenemethanol (FmOH), 2-methyl-6nitrobenzoic anhydride (MNBA), DMAP, $\mathrm{CH}_{2} \mathrm{Cl}_{2}, 23{ }^{\circ} \mathrm{C}, 93 \%$ (two steps); (c) TMSOTf, 2,6-lutidine, $\mathrm{CH}_{2} \mathrm{Cl}_{2}, 23{ }^{\circ} \mathrm{C}$; then $\mathrm{NaHCO}_{3}, 4,97 \%$; (d) 6, $\mathrm{Pd}\left(\mathrm{PPh}_{3}\right)_{4}$, CuI, $\mathrm{Et}_{3} \mathrm{~N}, \mathrm{Et}_{2} \mathrm{O}, 23$ ${ }^{\circ} \mathrm{C}, 61 \%$; (e) $\mathrm{Et}_{3} \mathrm{~N}$, THF; MNBA, DMAP, benzene, $23{ }^{\circ} \mathrm{C}, 66 \%$; (f) $\mathrm{AgNO}_{3}, \mathrm{THF}, \mathrm{H}_{2} \mathrm{O}, 23$ ${ }^{\circ} \mathrm{C}$; 2,6-lutidine, 73\%; (g) $\mathrm{Cu}(\mathrm{OAc})_{2}$, CuI, pyridine, THF, $60{ }^{\circ} \mathrm{C}, 59 \%$; (h) LHMDS, THF, toluene, $-78{ }^{\circ} \mathrm{C}$; $t$-BuLi; HOAc, $52 \%$; (i) TBAF, $o$-nitrophenol, THF, $23{ }^{\circ} \mathrm{C}$; (j) PivCl, $\mathrm{Et}_{3} \mathrm{~N}, \mathrm{CH}_{2} \mathrm{Cl}_{2}, 23{ }^{\circ} \mathrm{C}, 76 \%$; (k) $\mathrm{CH}_{3} \mathrm{C}(\mathrm{Ph})_{2} \mathrm{OOH}, \mathrm{VO}$ (acac) $)_{2}$, benzene, $23{ }^{\circ} \mathrm{C}, 28 \%$; (l) $\mathrm{AgPF}_{6}, \mathrm{DTBMP}, 14, \mathrm{CH}_{2} \mathrm{Cl}_{2}, 0{ }^{\circ} \mathrm{C}$; pyridine, 59\%; (m) Martin sulfurane, benzene, $23{ }^{\circ} \mathrm{C}$, $65 \%$; (n) TBAF, $o$-nitrophenol, $\mathrm{CH}_{3} \mathrm{CN}, 23{ }^{\circ} \mathrm{C}$; then $\mathrm{Et}_{3} \mathrm{~N} \cdot 3 \mathrm{HF}, 50 \%$. 